\title{
¿En qué sentido el raciopoetismo sirve como modelo de comprensión intensiva de la hermenéutica analógica?
}

\section{In what sense (meaning) ratiopoetism is useful as a model of intensive understanding in analogic hermeneutics?}

\author{
José BARRIENTOS RASTROJO \\ (Universidad de Sevilla)
}

Recibido: $11 / 05 / 2013$

Aceptado: 14/11/2013

\section{Resumen}

Este artículo conecta el raciopoetismo zambraniano con la hermenéutica analógica de Mauricio Beuchot. La ligazón se operativiza a través de cuatro niveles: (1) análisis del objeto hermenéutico; (2) indagación realizada desde una apertura horizontal del conocimiento, precedida por la crítica al modelo racionalista de la modernidad; (3) estudio de las posibilidades de profundización desde la categoría de $s u b$ tilitas y (4) meditación sobre la densidad hermenéutica desde el concepto zambraniano "saber de la experiencia". Estos cuatro estadios permitirán ascender desde la acepción textual de la hermenéutica, contemplada al inicio del trabajo, a una perspectiva de la disciplina como proferir, en el sentido descrito por Ebeling.

Palabras clave: Hermenéutica analógica, subtilitas, raciopoetismo, saber de la experiencia.

\begin{abstract}
This article links zambranian 'raciopoetismo' to Beuchot's analogic hermeneutics. This connection is implemented by means of four levels: (1) an analysis of hermeneutic object; (2) an inquiry made from an horizontal opening of the knowledge and preceded by a critic to rational model created at modernity; (3) a study of possibilities of deepening from 'subtilitas' and (4) a meditation on hermeneutic den-
\end{abstract}


sity based on the zambranian concept 'saber de la experiencia'. These four stages will let us climb from a textual meaning of hermeneutics, issued at the beginning of our work, to a discipline understood as utter ("proferir") as it is described by Ebeling.

Keywords: Analogic hermeneutics, subtilitas, raciopoetismo, experience knowledge ("saber de la experiencia").

\section{El objeto hermenéutico en María Zambrano y Mauricio Beuchot y la exigencia de su estudio}

Mauricio Beuchot y María Zambrano ${ }^{1}$ comparten una aproximación análoga 2 a la filosofía: entender el acto reflexivo como la posibilidad de descifrado y/o comprensión de entidades significativas. ${ }^{3}$ La reflexión zambraniana se identifica, en última instancia, con el acto de descifrar el sentir originario, mientras que la obra beuchotiana nos abre a una hermenéutica que, «según la definición o descripción dada por Ricoeur, es la ciencia y el arte de la interpretación de textos». 4

Esta primera aproximación evidencia una sutil distancia entre los objetos de la disciplina citados en cada autor: «sentir originario" frente a «textos". La lejanía, se

\footnotetext{
1 El mismo Mauricio Beuchot ha subrayado su cercanía a Zambrano en diversas publicaciones y en conversaciones que hemos mantenido con él. Así, explicaba en una entrevista publicada en Endoxa lo siguiente: "Alejandro Salcedo y Greta Rivara hablan de toda una racionalidad analógica, aledaña a la hermenéutica analógica. Por cierto que viene a ser una racionalidad muy cercana a la que propone María Zambrano, es decir, tratando de conjuntar lo literal y lo simbólico, lo científico y lo poético, lo metonímico y lo metafórico. Como se ve, la analogía tiene una raigambre hispana y latinoamericana muy fuerte" (cf. Arenas-Dolz, F.: "Hermenéutica, analogía y retórica. Entrevista a Mauricio Beuchot", Endoxa, 20, 2005, p. 688). La referencia al mundo órfico-pitagórico en relación al descenso a los ínferos dantesco glosado por Zambrano también es rescatado por Beuchot en su obra Metáforas de nuestra vida (cf. Beuchot, M.: Metáforas de nuestra vida. Antropología e interpretación, Huelva, Hergué, 2011, pp. 37-38).

2 Usamos aquí el adjetivo "análogo" en el sentido más beuchotiano: una experiencia fontanal común con derivaciones propias que no les hace abandonar nunca la comunidad primigenia.

${ }^{3}$ La filosofía y la hermenéutica son necesidades básicas en nuestro mundo según Mauricio Beuchot, puesto que nos encontramos en "un tiempo indigente, menesteroso de sentido" (Beuchot, M.: Metáforas de nuestra vida, op.cit., p. 98). El positivismo nos ha introducido en una existencia de referencias planas y unívocas, donde se ha olvidado que la realidad está constituida también de símbolos que demandan ser comprendidos. "El símbolo es un signo con, al menos, doble significado. Uno directo y otro escondido" (Beuchot, M.: Hermenéutica analógica, símbolo, mito y filosofía, México DF, UNAM, p. 14). La propuesta analógico-icónoca de Beuchot es una intelección afín en ciertos puntos al saber evidencial y experiencial de Zambrano, pues permite desde sus circunvoluciones específicas rastrear esos fondos ocultados.

4 Beuchot, M. - Arenas-Dolz, F.: Hermenéutica en la encrucijada. Analogía, retórica y filosofía, Barcelona, Anthropos, 2008, p. 21.
} 
puede aseverar, es tan amplia que debería constatar la inconmensurabilidad entre los dos autores. Sin embargo, un mayor detenimiento en los significados quiebra el abismo. La hermenéutica de Beuchot excede la de aquellos exégetas bíblicos o la de los hermeneutas retóricos renacentistas que reducían la interpretación a la clarificación de términos. 5

Primero, el objeto interpretativo de nuestro pensador incluye «textos hiperfrásticos, es decir mayores que la frase», ${ }^{6}$ ampliándose la semántica de los mencionados «textos».

En segundo lugar, se trasciende una consideración hermenéutica afincada en un subjetivismo de tipo schleiermachiano, ${ }^{7}$ puesto que Beuchot apunta a objetos hermeneutizables que no siempre son seres conscientes y humanos. Así, cuando la hermenéutica acepta dentro de su acervo al acto psicoanalítico, empezamos a escapar de las limitaciones de la teoría del sujeto moderno.

En tercer lugar, una época fundada en la ontologización de la hermenéutica no puede aceptar una perspectiva restrictiva del objeto hermenéutico, es decir, la textual, puesto que sería retroceder a hermenéuticas previas a la época de su ontologización en el siglo XX. Las décadas desvirgadas hermenéuticamente por Heidegger y Gadamer, y a pesar de las críticas de Hirsh e Betti, ${ }^{8}$ demandan que los citados «textos» den cabida a entidades que trasciendan lo escrito e incluso lo dicho. ${ }^{9} \mathrm{La}$ Hermenéutica en la encrucijada especifica que «el texto puede ser escrito, oral, actuado, esculpido, etc...».10 Por tanto, la herramienta beuchotiana se acomoda tanto a la exégesis de una obra pictórica, de una acción ética, de una decisión política o al citado acto psicoanalítico. ${ }^{11}$

\footnotetext{
5 Cfr. Ferraris, M.: Historia de la hermenéutica, trd. Jorge Pérez de Tudela Velasco, Madrid, Akal, 2000, pp. 30-36.

6 Beuchot, M.: Tratado de hermenéutica analógica. Hacia un nuevo paradigma de interpretación, México DF, UNAM-Ítaca, 2000, p. 15.

7 Según la interpretación de Schleiermacher realizada por Wilhem Dilthey.

8 Cfr. Ferraris, M.: Historia de la hermenéutica, op.cit., pp. 323-332. Véase también Grodin, J.: Introducción a la hermenéutica filosófica, Barcelona, Herder, 1999, pp. 180-184.

9 De hecho, Beuchot ha estudiado las vinculaciones entre Hermenéutica y Ontología en varias de sus obras. Véase, por ejemplo, el capítulo "Hermenéutica analógica y ontología analógica" en Hermenéutica en la encrucijada (pp. 101-114) o el capítulo "Ontología y hermenéuticas analógicas" en el Tratado de hermenéutica analógica (pp. 95-120).

10 Beuchot, M. - Arenas-Dolz, F., Hermenéutica en la encrucijada, op.cit, p. 61. A pesar de ello, Beuchot se une al metodologismo de Betti o Hirsh puesto que pretende ofrecer herramientas para gestar la interpretación.

11 Muestra de estas derivas se encuentran en diversas obras. La ética puede encontrarse en Beuchot, M.: Ética, Torres asociados, México DF, 2004 y en Beuchot M. - Arenas-Dolz, F.: Hermenéutica en la encrucijada, op.cit, pp. 121-132. La discusión sobre la política se clarifica en Beuchot, M.: Filosofia Política, Torres Asociados, México DF, 2004, pp. 101-108. La indagación en el psicoanálisis aparece en Beuchot, M.: Tratado de hermenéutica analógica, op.cit, pp. 153-168.
} 
Puestas así las cosas, Zambrano y Beuchot acotan un objeto hermenéutico donde se requiere tanto lo epistémico como lo ontológico, esto es, tanto una metodología de interpretación como una comprensión metafísica del acto de comprender. La hermenéutica no sólo es un modo de entender el mundo sino de hacer mundo. ${ }^{12}$ Esta circunstancia pone de relieve la radical urgencia de posicionarnos en relación a la hermenéutica, pues en ello no sólo nos va el mundo sino la vida debido a nuestra condición temporal (y secular). Cuando la hermenéutica no excede las fronteras de un cognitivismo desapasionado, esto es objetivo, y distanciado de la existencia, es decir como pura epistemología, funcionará como una herramienta sin capacidad para transformar la esencia del entorno. Ahora bien, cuando la hermenéutica se alza con potencia de construcción ontológica, el destino del propio sujeto se ve comprometido gracias a los avances de esta área de conocimiento.

Retomando el tema de este epígrafe, la indagación en la entraña hermenéutica es la clarificación interpretativa de las formas ontológicas. El compromiso con una modalidad interpretativa implica la avenencia con un modo de ser. La propuesta que se realizará en estas líneas parte de la teoría trazada por Mauricio Beuchot, que se compara con la de Zambrano, la cual servirá para completar las estructuras comprensivas del mexicano desde una dimensión intensiva.

\section{Interpretar I: apertura horizontal}

\section{II.1. La crítica al modelo unívoco y lógico-argumental}

Mauricio Beuchot suele incluir el univocismo, o la tendencia a aceptar una única voz o interpretación, dentro del positivismo moderno. ${ }^{13}$ Esta tendencia filosófica se describe con dos características, criticadas por nuestro autor. La primera es la tendencia de la modernidad a afirmar una definición en número singular de los contenidos a pesar de que se parte de un mundo polifónico y coral:

En su aspecto rudimentario, el positivismo adoptó la forma cientificista del siglo XIX, en la que sólo valía la interpretación reduccionista cientificista de cualquier texto o

\footnotetext{
12 En el campo de la expertise Martínez Albéniz llega a la misma conclusión: el experto no sólo evalúa elementos ajenos a él sino que genera un mundo desde esa interpretación: "el experto no es más un develador de que las cosas están socialmente construidas (...) sino un productor de fatiches" (Martínez de Albéniz, I.: "La reconversión de Sísifo: identidad y expertise" en Apodaka, E. - Merino, L. - Villareal, M. (eds.): Crisis y mutaciones de la expertise. Escenarios, políticas y prácticas del conocimiento experto, Zarautz, Ascide, 2012, p. 232).

13 Cf. Beuchot, M.: "Hermenéutica analógica y crisis de la modernidad", Revista de la UNAM, 13, 1998, pp. 567-568.
} 
acción o evento; siempre una sola y única interpretación. Tenía que ser unívoca con un significado unívoco y sin dejar ningún lugar a la ambigüedad14

De forma equivalente, se expresa Zambrano en Los bienaventurados: si, en la modernidad, una teoría no ofrece una visión clara, evidente y unívoca de la realidad se la degrada hasta cercenar su validez. «Si una respuesta no ofrece estos caracteres que la elevan a la categoría de imperativo no es reconocida como tal y acaba -o empieza- por ser desechada simplemente». ${ }^{15}$

María Zambrano incardina este absolutismo univocista en el poder que se ejerce para dilapidar la incertidumbre plurívoca de la vida y alcanzar un asidero y, por ende, descanso existencial. Más allá del fluyo constante, en el que se incardina la multiplicidad de las visiones del poeta, el científico consigue (y necesita) verdades que lo protejan del caos (aleatorio) del mundo. La aceptación de lo plurívoco se corresponde con un sujeto a la intemperie, lo cual le impide protegerse de los fenómenos naturales, con el consiguiente riesgo de perecer.

Ante la inseguridad en que el griego se siente en medio del fluir incesante de las cosas naturales, y para salvarse de ellas, acude al pensamiento, creyendo implícitamente ya (...) dos cosas: que existía aparte de la realidad fluidiza (...) otra realidad inmutable, permanente y absoluta, sustraída al tiempo y a toda relatividad 16

Arropado por esa realidad fija (y unívoca), «el hombre se sintió seguro y creó el dogmatismo metafísico racionalista y absolutista». ${ }^{17}$ No objetaremos nada a esta búsqueda de amparo de un sujeto que busca su propia salvación epistémica y existencial. Según la zambraniana Persona y democracia,

Con ella [con la racionalidad unívoca], el hombre se libraba de la inseguridad de vivir en un medio sujeto a cambio incesante, y de la angustia de sentirse huésped de un lugar donde todo está sujeto a la imprevisible voluntad de los dioses que, a su vez, eran movidos por las mismas pasiones que los hombres. En lugar del movimiento incesante en que las cosas naturales nacen y mueren (...), se había encontrado un orden racional espontáneo 18

La preocupación ante esta aproximación unívoca se asienta en el hecho de que se están sembrando las semillas de una infidelidad a la realidad (que es multívoca)

\footnotetext{
14 Beuchot, M.: Tratado de hermenéutica analógica, op.cit, p. 46.

15 Zambrano, M.: Los bienaventurados, Madrid, Siruela, 2004, p. 81.

16 Zambrano, M.: Senderos. Los intelectuales en el drama de España. La tumba de Antígona, Barcelona, Anthropos, 1989, p. 74.

17 Ibid., p. 75.

18 Zambrano, M.: Persona y democracia, Madrid, Siruela, 1996, p. 74. El contenido de los corchetes es nuestro.
} 
con anhelo por acallar miedos. Así, el racionalismo univocista (moderno) polinizará todo el pensamiento e impondrá su univocismo radical como única posibilidad. Entonces, se dictaminará sin derecho a réplica que la realidad es una. Se hace inviable la dualidad de visiones contradictorias y, en suma, la multivocidad.

Aquí, alcanzamos el punto crítico del asunto: la hegemonía de una modalidad particular de verdad, la racionalista, es decir, la extensión «sin más de los principios de la Razón a la realidad toda». ${ }^{19}$ He aquí la segunda crítica al modelo positivista: no sólo es unívoco sino que impone como paradigma un modo racional específico, el lógico-argumental, que elimina el resto de las formas comprensivas. Las concepciones narrativas o poéticas, y en general las artísticas, quedan obstruidas, pues ni siquiera adquieren carta de autonomía para entrar en el ágora de la discusión, en la medida en que sus criterios de validez se alejan de los de la racionalidad imperial, absoluta de tipo científico y metodológico. ${ }^{20}$

Quizás, la racionalidad lógico-argumentativa debería haber derivado, en coherencia, al aforismo siente del Tractatus wittgenteniano, a saber, mostrar silencio delante de aquellos campos ajenos a las propias competencias. Por el contrario, su decisión soberbia subyugó la libertad humana y ha teñido el destino de la Europa moderna con un dictatorial «Nada entregado al azar; todo traspasado de orden, número y medida». 21

Aun se puede recrudecer el asunto: esta razón, en lugar de ir a aprehender la realidad crea su propio sistema y teorías para, más tarde, buscar la justificación de sus asertos. No sólo clausura y acotan las formas de acceder a la realidad, sino que «quiso transformar la verdad». ${ }^{22}$ Aquí, ubicamos la crítica de autores del siglo XX como Feyerabend, ${ }^{23}$ quienes aseveran que la altanería de la modernidad transforma su razón en un medio para crear teorías que sólo son fieles a ideologías de quien las ostenta. 24

Beuchot subraya, también, este aspecto cuando anima a la recuperación de la razón simbólica: «más allá de la razón técnica hay que recuperar la razón simbólica, la cual tiene el efecto de recuperar el nexo con la realidad» 25 .

19 Ibid., p. 111. Las cursivas son nuestras.

20 La razón arquitectónica frente a la razón de la sierpe, en términos de Zambrano.

21 Zambrano, M.: La agonía de Europa, Madrid, Trotta, 2000, p. 37.

22 Zambrano, M.: La confesión: género literario, Madrid, Siruela, 1995, p. 15

23 Cf. Feyerabend, P.: Contra el método, tr. Eduardo Subirats Rüggeberg, Barcelona, Planeta DeAgostini S. A., 1993.

24 Esta misma crítica podría hacerse desde la sociología del conocimiento. Por ejemplo, Karl Mannheim, en Ideología y utopía, explica cómo durante cierto periodo de tiempo la intelligentsia, o capas del saber sirvieron como vasallos al poder (cf. Mannheim, K.: Ideología y utopía, tr. Salvador Echevarria, Fondo de Cultura Económica, Madrid, 1997). Este es el sentido de toda la obra foucaultiana y sus arqueologías gnoseológicas para desvelar la fuente auténtica de la verdad.

25 Beuchot, M.: Hermenéutica analógica, símbolo, mito y filosofia, op.cit., p. 53. Las cursivas son nuestras. 
A pesar de este intento de dictadura, la vida escapa constantemente de las concreciones racionalistas y muestra de ello será el auge en el siglo XX de las filosofías vitalistas. 26 La vida reclamará, por un lado, la recuperación de la cordura de la razón mediante una mayor fidelidad de la comprensión a lo que es y, por otro, una reconsideración de la razón que permita un cromatismo acorde a la polifonía coral de la existencia. No se perseguirá un relativismo sin orden ni concierto sino una orquestación de las bases de la racionalidad que asuma la legitimidad de todas las notas musicales. En esta marea, navegará el analogismo beuchotiano, que veremos más adelante.

\section{II.2. Lo equívoco y lo poético}

$\mathrm{Al}$ otro lado de lo unívoco queda lo plurívoco, lo equívoco, 27 lo metafórico o, en general, la apertura sin restricciones. El Tratado de hermenéutica analógica coloca la vocación equívoca junto al relativismo, el subjetivismo y lo incardina en el romanticismo y la posmodernidad. ${ }^{28}$ Lo equívoco abre mundo frente a lo restringido de lo unívoco. ${ }^{29}$ Ésta observación es idéntica a lo «poético» en María Zambrano:

26 Éste fue el descubrimiento de las filosofías vitalistas del siglo XX: "La reacción contra el positivismo se hace notar especialmente en tres grandes áreas: en el de la filosofía, en el de la literatura y en el de la sociedad. En el área de la filosofía, la reacción contra el positivismo provoca una exaltación de la vida y del vitalismo en todas sus manifestaciones (intuicionismo, irracionalismo, acción directa, elan vital, impulso sexual...), de acuerdo con el mensaje nietzscheano" (Abellán, J.L.: María Zambrano. Una pensadora de nuestro tiempo, Barcelona, Anthropos, 2006, p. 87).

27 La disquisición entre lo unívoco y lo equívoco aparece en diversas partes de la obra beuchotiana. Además de explicitarse en su Tratado de hermenéutica, un resumen de su posición se puede leer Perfiles esenciales de la hermenéutica (Beuchot, M.: Perfiles esenciales de hermenéutica, México DF, Fondo de Cultura Económica, 2008, pp.88 y ss). Por otra parte, una aplicación al campo antropológico puede encontrarse en M.Beuchot, Metáforas de nuestra vida, op.cit., p.17 y ss.

${ }^{28}$ Cf. Beuchot, M.: Tratado de hermenéutica analógica, op.cit., pp. 39-45 y 47-51. De hecho, romanticismo y positivismo litigan como dos hermanos, "dos hijos, gemelos pero enemigos (...) que son el romanticismo y el positivismo. El romanticismo se opone al cientificismo de la Ilustración, y resucita el significado alegórico, pone muy de relieve los símbolos, estudia los mitos, se interesa por las religiones, por lo misterioso" (Beuchot, M. - Arenas-Dolz, F.: Hermenéutica en la encrucijada, op.cit., p. 27).

29 Sobre la consideración de esta dualidad analógica puede consultarse la citada entrevista aparecida en Endoxa en 2005. Allí, señala: "la hermenéutica analógica intenta superar la distensión que actualmente se observa entre las que se pueden llamar hermenéuticas unívocas (cientificistas) y hermenéuticas equivocistas (relativistas). Las últimas proliferan ahora, en esto que se denomina tardomodernidad o posmodernidad. Se trata de evitar la rigidez de las primeras y la excesiva apertura de las segundas. Y tiene la ventaja de que en la analogía predomina la diferencia sobre la identidad; es decir, aunque está a mitad de camino entre la univocidad y la equivocidad, participa más de esta última que de aquélla. Esto le permite oscilar en difícil equilibrio entre el sentido literal y el alegórico" (ArenasDolz, F.: "Hermenéutica, analogía y retórica. Entrevista a Mauricio Beuchot", op. cit., p. 685). En cuanto al análisis de la posmodernidad, existe un completo estudio sobre la orientación hermenéutica 
el poeta se fusiona con la realidad en lugar de aplicar una distancia objetiva unívoca con el mundo. Escucha y acepta cada uno de los matices de la realidad en el propio lenguaje en que éste se gesta, al punto de que no impone una metodología comprensiva que coartaría la inmediatez de ese conocimiento. Por ello, no se ejerce resistencia o violencia ante lo que circunda a la persona; 30 por el contrario, abre sus brazos intelectuales como un árbol y se opone a todo intento de limitación. 31

Por ende, se da curso a la posibilidad de una razón que no pertenece a poderes fácticos consolidados sino que florece a partir del intento de ser sostenida por todos y dirigida hacia todos, es decir, amparada por todos los agentes del conocimiento y destinada a cualquier objeto cognoscible. ${ }^{32}$ Esta razón, que excede el univocismo lógico-argumental, funciona como una luz que restaura las oscuridades generadas por comprensiones restrictivas.

Lo que sucede no puede ser debido solamente a la apasionada, sostenida, atención, sino a que la razón, por sí misma, ilumina y abre los sentidos mismos para penetrar en ellos, lo que ha sido echado al olvido (...). Por tanto, la razón, la mismísima razón, habría de iluminar y operar al modo de la luz, deslizándose por lugares y poros invisibles; y en cuanto a las tinieblas, rodeándolas, penetrando en ellas como la sierpe 33

Esta concepción posee riesgos, puesto que el equivocismo, al carecer de criterios y al suponer apertura total, forja una perspectiva tan «pragmáticamente inconsistente» 34 como la de la unívoca. En la medida en que lo plurívoco se autoafirma

beuchotiana y los autores de esta corriente titulado Posmodernidad, hermenéutica y analogía (cf. Beuchot, M.: Posmodernidad, hermenéutica y analogía, México DF, Universidad IntercontinentalMiguel Ángel Porrúa, 1996).

30 Realidad muy diferente es la consideración del concepto "filosofía". Aunque poesía y filosofía irradian de un centro común, la admiración ante lo real, la filosofía sólo nace después de que el pensador aplica una violencia respecto a la realidad (cf. Zambrano, M.: España, sueño y verdad, Barcelona, Edhasa, 2002). Mauricio Beuchot también ha estudiado las vinculaciones entre filosofía y poesía en el capítulo "El entrecruce de filosofía y poesía" dentro de Metáforas de nuestra vida (cf. Beuchot, M.: Metáforas de nuestra vida, op.cit., pp. 71-89). Según el filósofo mexicano, ambas disciplinas se "cruzan en un instante analógico" (p. 78), si bien, avisa del peligro de "que se toquen", puesto que para él no deben confundirse (p. 77).

31 "Sobre los hombros del poeta anidan también los pájaros; con los brazos abiertos ante la creación, el poeta se abre a todas las cosas, se ofrece íntegramente sin ofrecer resistencia a nada, quedándose vacío quieto para que todas las figuras aniden en él; se convierte en simple lugar vacío donde lo que necesita asentarse y vaga sin lugar, encuentre el suyo y se pose. Tal puede ser el símbolo del poeta" (M. Zambrano: Pensamiento y poesía en la vida española, Madrid, Endymion, 1996, p. 48).

32 En términos zambranianos, "la razón no está para que nadie la tenga, sino para que entre todos la sostengamos. Y sólo así es no ya viviente, sino vital, simplemente vital" (Zambrano, M.: Cartas de la Pièce (correspondencia con Agustín Andreu), Valencia, Pretextos-Universidad Politécnica de Valencia, 2002, p. 169).

33 Zambrano, M.: De la aurora, Madrid, Tabla Rasa, 2004, pp. 51-52. Las cursivas son nuestras.

34 Cf. Beuchot, M.: Tratado de hermenéutica analógica, op.cit, p. 42. Esta inconsistencia pragmática 
como posibilidad preeminente, se hace deudora de la crítica al escepticismo: si todo es igual de válido (puesto que la apertura impide cualquier negación) ¿cómo se legitima su postura sobre su rival?

Ítem más: la aceptación igualatoria de todos los frentes disuelve la posibilidad de establecer jerarquías entre las diversas apuestas teóricas o prácticas.

\section{II.3. Lo analógico y la razón poética}

Las salidas que afirman el cromatismo sin caer en el abismo del «anything goes» son el analogismo beuchotiano y la razón poética zambraniana.

La analogía consiste en evitar la tan temida unificación o identificación simplificadora, la monolitización del conocer, la entronización parmenídea de la mismidad; pero también consiste en evitar la nociva equivocidad, la entronización heraclítea de la diferencia, la coronación del relativismo, que es otro monolitismo, sólo que atomizado 35

La figura resultante se armoniza con el origen del dios al que se atribuye el origen de la Hermenéutica. Hermes se solía aparecer en el cruce de caminos, «punto en el cual no es del todo claro, pero tampoco del todo ambiguo, el sentido». ${ }^{36}$ Asimismo, Hermes se identificaba con un semidios que conectaba a los hombres con los dioses, es decir, traía una fuente común (la palabra divina) a los diversos lenguajes humanos). 37

se materializa a la hora de tomar una decisión en la vida política o ética. Si todo es igualmente válido, ¿qué haría privilegiar las razones de las Naciones Unidas sobre los desafueros de un Tercer Reich?

35 Ibid., p. 43. Según Hermenéutica en la encrucijada, "nos ayudará a evitar y superar la intervención unívoca (moderna y positivista) y la interpretación equivocista (posmoderna y romántica)" (Beuchot, M. - Arenas-Dolz, F.: Hermenéutica en la encrucijada, op.cit., p. 50). La ética de nuestro pensador reincide en que "una hermenéutica analógica evitará la interpretación univocista de los cientificismos y positivismos, al igual que la interpretación equivocista de los relativismos y subjetivismos" (Beuchot, M.: Ética, op.cit., p. 43). Asimismo, una hermenéutica analógica es simbólica, puesto que el símbolo reúne lo separado sin caer en una confusión sin jerarquías (cf. Beuchot, M. Metáforas de nuestra vida, op.cit., p. 37; Beuchot, M. Hermenéutica analógica, símbolo, mito, op.cit, pp. 27-32) 36 "Hermes, a quien tradicionalmente se ha hecho el creador de la hermenéutica - ya que también se le atribuye el origen del lenguaje y de la escritura-, tenía por costumbre aparecerse en los cruces de los caminos, en las encrucijadas, como dando a entender que la interpretación se requería sobre todo donde se juntaban caminos extremos, que iban en sentidos contrarios. Se tocaban en los límites, se cruzaban en ese punto en el cual no es del todo claro, pero tampoco del todo ambiguo, el sentido. Y ahí se da la analogía, pues ésta es lo intermedio entre la univocidad - clara y distinta- y la equivocidad completamente relativa e irreductible. Así, pues, una hermenéutica analógica es la que trata de responder fielmente a la llamada de Hermes, de interpretar reconociendo que hay pérdida de significado, pero con la suficiencia que nos permita una comprensión bastante del texto" (Beuchot, M. - Arenas-Dolz, F.: Hermenéutica en la encrucijada, op.cit., p. 17).

37 "La palabra griega hermeneios se refiere al sacerdote del oráculo de Delfos. Esta palabra, el verbo hermeneuin y el sustantivo hermeneia hacen referencia al dios mensajero de pies alados Hermes, de 
La hermenéutica analógica admite «que pueda haber no una única interpretación válida, sino un pequeño grupo de interpretaciones válidas, según jerarquía, que puedan ser medidas y controladas con arreglo al texto y al autor». 38 Beuchot muestra más adherencias a la diversidad, sin que esta apetencia obligue a descender a una univocidad a ultranza. Se conjuga una diversidad esencial con una univocidad «de modo relativo o secundario».39

Concretando: la hermenéutica analógica reconoce una fuente unívoca y asevera una pluralidad de interpretaciones, jerarquizándose las últimas en función de la fidelidad a la fuente y al intérprete. Estos últimos puntos, que no aparecían con claridad en las primeras obras beuchotianas, ${ }^{40}$ conforman los criterios de regulación y ordenación de las interpretaciones.

Así como en epistemología o teoría del conocimiento hablamos de grados de aproximación a la realidad en las teorías, así también en hermenéutica hablamos de grados de aproximación al significado del texto. No hay sólo una interpretación válida, sino varias, pero no todas lo son; y aun entre estas varias, se ha de establecer una jerarquía o grados de adecuación al texto, ya sea porque se apresan sólo algunos aspectos, ya sea porque hay interpretaciones más completas o más adecuadas. Unas pueden ser verdaderas pero muy incompletas; otras completas, pero muy falsas; otras, en cambio, pueden tener elementos falsos, pero no en la totalidad, y otras que tengan pocos aciertos. Podrá extrañar que hablemos de grados de aproximación. Pero dos interpretaciones pueden ser verdaderas, sólo que una más completa que otra, más rica, más abarcadora, y, en ese sentido, más verdadera 41

cuyo nombre supuestamente se derivan (¿o viceversa?). Significativamente, se asocia con la función de convertir lo que está más allá de la comprensión humana en una forma que la inteligencia humana pueda captar” (Palmer, R.: ¿Qué es la hermenéutica? Teoría de la interpretación en Schleiermacher, Dilthey, Heidegger y Gadamer, tr. Beatriz Domínguez Parra, Madrid, Arcolibros, 2002, p. 30).

38 Beuchot, M.: Tratado de hermenéutica analógica, op.cit, p. 11.

39 "En cambio, lo análogo es lo que se predica o se dice de un conjunto de cosas en un sentido en parte idéntico y en parte distinto, predominando la diversidad; es idéntico según algo, según algún respecto, y diverso de modo simple (simpliciter diversum et secundum quid idem); esto es, diverso de por sí y principalmente, y sólo es idéntico o semejante de modo relativo o secundario" (Beuchot, M.: Tratado de hermenéutica analógica, op.cit., p. 38)

40 Los textos del Tratado de hermenéutica analógica (1997) se mueven en la tesitura del siguiente, que nos deja con sed de una mayor concreción metodológica en torno a los criterios para dictaminar cómo evaluar y ordenar diferentes interpretaciones de un mismo texto o manifestación hermeneutizable: "No se trata de sostener una única interpretación como válida, sino varias, pero dentro de cierto límite, y puede decirse que una entre ellas se acerca más a la verdad, y, por supuesto, que otras se alejan de ella. Se trata de poder comparar interpretaciones como verdaderas o falsas, de modo que se evite el equivocismo de los relativistas, que las ven a todas como válidas y complementarias" (Beuchot, M.: Tratado de hermenéutica analógica, op.cit., p.51) Estas líneas abren la cuestión de la materialización de tamaña tarea.

41 Beuchot, M., Arenas-Dolz, F.: Hermenéutica en la encrucijada, op.cit., p. 73. Las cursivas son nuestras. 
La fuerza interna de cada interpretación depende de su riqueza de elementos y de su capacidad para contener y expresar los puntos básicos del texto y la propia realidad del intérprete, de la intentio lectoris. 42 «Siendo los criterios de evaluación de los argumentos dentro de un contexto analógico (...) los mismos que en cualquier contexto lógico, o de lo razonable; se tiene aquí la ventaja de que la analogicidad promueve y facilita la confluencia, buscando un término medio común, en el cual los opuestos se acercan, y encuentran una mediación».43

Como intuirá el estudioso de Zambrano, el espíritu analógico es acorde, en el aspecto mediador, con la razón-poética. Ésta se yergue como un «saber de reconciliación que intenta paliar extremismos».44

Poesía y pensamiento se nos aparecen como dos formas insuficientes; y se nos antojan dos mitades del hombre: el filósofo y el poeta. No se encuentra el hombre entero en la filosofía; no se encuentra la totalidad de lo humano en la poesía. En la poesía, encontramos directamente al hombre concreto, individual. En la filosofía, al hombre en su historia universal, en su querer ser. La poesía es encuentro, don. Hallazgo por gracia. La filosofía busca, requerimiento guiado por un método 45

A pesar de que el concepto «razón poética» se atribuye a María Zambrano, surge originariamente en el poeta Antonio Machado, amigo del padre de la filósofa y alumno de su abuelo paterno. Así, lo hace ver la filósofa malagueña:

Para Machado la poesía es cosa de conciencia, esto es, de razón, de moral de ley. Y esa unidad moral, poética y filosófica arranca de su entereza humana. "Poesía y razón se completan y requieren una a otra. La poesía vendría a ser el pensamiento supremo por captar la realidad intima de cada cosa, la realidad fluyente, movediza, la radical heterogeneidad de ser" 46

42 "Entonces, ¿quién determina el significado? ¿El intérprete, la estructura del texto, o la intención del autor? Ya los medievales hablaban de la intentio auctoris y de la intentio lectoris, y Umberto Eco habla de la intentio operis o intentio textus. Nosotros hablaríamos, más que de una intención del texto, de la conjunción o encuentro de la intención del autor y de la intención del lector. En parte se puede recuperar la intención del autor, y en parte ya está contaminada de la intención del lector. Ciertamente la intencionalidad del lector se mete en la interpretación; pero no a tal punto que se cambie totalmente y se pierda la intencionalidad del autor" (Beuchot, M.: Tratado de hermenéutica analógica, op.cit., p. 56). La Hermenéutica en la encrucijada coincide en que "entre ambas se da una dialéctica que trata de balancear las dos fuerzas" (Cfr. Beuchot, M. - Arenas-Dolz, F.: Hermenéutica en la encrucijada, op.cit.,p. 21)

43 Beuchot, M. - Arenas-Dolz, F.: Hermenéutica en la encrucijada, op.cit.,p. 91.

44 Maillard, Ch.: La creación por la metáfora. Introducción a la razón-poética, Barcelona, Anthropos, 1992, p. 28.

45 Zambrano, M.: Filosofía y poesía, Madrid, Fondo de Cultura Económica, 2001, p. 13.

46 Zambrano, M.: Las palabras del regreso, Salamanca, Amaru ediciones, 1995, pp. 183-184. El texto citado de Machado se encuentra también en Zambrano, M.: Senderos, op.cit. ,p. 68. Las cursivas son de la autora. 
Machado considera indisociable filosofía y poesía. Su Juan de Mairena considera que el auténtico poeta o bien posee una metafísica a sus espaldas o queda reducido a «un señorito que compone versos». 47

Las metáforas que explicitan la naturaleza mediadora de la razón poética son múltiples. En clave bíblica, Zambrano asevera que «en el principio era el logos. Sí, pero... el logos se hizo carne y habitó entre nosotros, lleno de gracia y de verdad».48 De ahí, la necesidad de que para alcanzar la verdad (la interpretación más válida en el espíritu beuchotiano) haya de dar a luz una modalidad de comprensión que integre lo unívoco de la racionalidad lógico-argumental y la equivocidad poética. Ese maridaje constituye un centro del que mana como dos radios filosofía y poesía y que, en camino inverso, nos conducen a la razón poética. 49

La razón-poética se concreta en géneros como el ensayo filosófico, las guías o las autobiografías intelectuales, pues los contenidos de estos escritos tocan al sujeto individual sin abandonarse a un subjetivismo cuyo criterio de verdad se diluya en un sentimentalismo informe, pero tampoco queda en un objetivismo ajeno a la persona y a su vivencia-experiencia. Este conocimiento destila verdades que abrazan una transcendencia tan válidas para cada sujeto (puesto que narran experiencias vinculadas con una comunidad de la que todo sujeto participa) como intransferibles y dependientes de la realidad vivida por cada persona.

Zambrano precisa esta teoría refiriéndose a la Guía de Miguel de Molinos, las Coplas a la muerte de mi padre de Jorge Manrique, las Epistolas de Séneca o la Antígona de Sófocles. Todas ellas unen la concreción de una vivencia espacio-temporal-personal con el descubrimiento de un elemento común que trasciende lo individual como la muerte, la injusticia, el ascenso espiritual o la limitación humana. Ni que decir tiene que es posible aquí descender al analogismo beuchotiano: una misma fuente entrañada para una sinfonía de interpretaciones.

Desde la perspectiva política y social, la razón poética nos conduce a la democracia. Esta forma de gobierno «es la liberación y disolución de todo absolutismo»,50 sin que se corra el peligro de una confusión equívoca, puesto que estamos en la «unidad de la multiplicidad, del reconocimiento, por tanto, de todas las diversidades».51 A pesar del riesgo equívoco por la policromía de opiniones, Persona y

\footnotetext{
47 "Todo poeta - dice Juan de Mairena- supone una metafísica; acaso cada poema debiera tener la suya -implícita, claro está, nunca explícita- y el poeta tiene el deber de exponerla por separado, en conceptos claros. La posibilidad de hacerlo distingue al verdadero poeta del mero señorito que compone versos" (Antonio Machado citado en Zambrano, M.: Senderos, op.cit., p. 64).

48 Zambrano, M.: Filosofía y poesía, op.cit., p. 25.

49 "El pensamiento irradia del mismo centro que la poesía. Podía esto haber sucedido por separado, siendo poesía y filosofía así al modo de dos radios, de dos caminos que parten del mismo centro y se dirigen a un horizonte tan amplio y lejano que, aunque lo que se vislumbre sea un círculo, queden a la vista estos radios separados por una especie de vacío incalmable" (Zambrano, M.: España, sueño y verdad, op.cit., p. 208).

50 Zambrano, M.: Persona y democracia, op.cit., p. 202.

51 Ibid, p. 204.
} 
democracia defiende, con optimismo, que «el orden de una sociedad democrática está más cerca del orden musical que del orden arquitectónico».52 No aparece el ruido porque existe un orden que no es impuesto coercitivamente por una instancia superior sino que es construido solidariamente por todos. La sinfonía democrática sólo es posible si permite escuchar cada una de las notas; la ausencia de sólo una de ellas quebraría la armonía creada.

Concluyamos: aunque en la obra de Zambrano no quedan tan claros los criterios para dirimir la jerarquía de cada opción y para dar la pintura general cuando es trazada por varias manos (como en el caso de Beuchot), esta primera aproximación describe cómo ambos avivan la ampliación del conocimiento desde una consideración horizontal. Por una parte, y más allá de la demarcación univocista cientificista, se crean nuevas vías de comprensión de la realidad que escapan al reduccionismo racionalista. Por otra parte, y trascendiendo la confusión inducida por una proliferación descontrolada de interpretaciones, la analogía propone criterios de demarcación y jerarquización. Por consiguiente, los senderos abiertos por Zambrano son concretados de modo maestro por Beuchot.

La comprensión se puede recorrer también en un sentido vertical. No sólo se trata de disponer de más contenidos sino de insights mejores y más profundos. Así, el actual desafío demanda apartar el velo de las verdades alcanzadas (sea esta una o cien) y alcanzar su entraña. «La hermenéutica -al igual que la pragmática-busca el nivel más profundo de la significación del texto, lo más profundo y exhaustivo que se pueda. Trata de pasar las estructuras aparentes o superficiales, y llegar hasta las estructuras recónditas o profundas». ${ }^{53}$ La herramienta de Beuchot será la subtilitas, Zambrano la completará con el saber de la experiencia o la experiencia de la vida.

\section{Interpretar II: apertura vertical. 54 La subtilitas como descubrimiento modulador del argumento}

Un segundo envite con la analogía nos descubre que su misma entraña no es unívoca, esto es, dada y definida una vez para siempre, sino analógico-dinámica, es decir, equívoca en el sentido temporal sin perder un centro unívoco:

\footnotetext{
52 Ibid., p. 206.

53 Beuchot, M. - Arenas-Dolz, F.: Hermenéutica en la encrucijada, op.cit., p.22. En esta dirección, María Zambrano entiende su proyecto filosófico como el proceso de "descifrar el sentir originario" (cf. Marset, J.C.: María Zambrano. I. Los años de formación, Sevilla, Fundación José Manuel Lara, 2004, p. 318; AA.VV.: María Zambrano. Premio Miguel de Cervantes, 1988, Barcelona, AnthroposMinisterio de Cultura-Dirección General del Libro y Bibliotecas, 1989, p. 16 y 50 y Zambrano, M.: Filosofía y educación, Málaga, Ágora, 2007, p. 57).

54 Beuchot hace referencia a los tipos de desarrollo, horizontal y vertical, en relación con la promoción de la innovación: "Veamos el modo como se realiza la innovación en hermenéutica. Es conve-
} 
La analogía no es un cómodo colocarse en un lugar intermedio, sino un oscilar activamente, de manera prudencial, entre extremos, para encontrar la proporción adecuada y conveniente 55

En consecuencia, la analogía requiere la acción de su propia etimología para actualizarse a lo largo del tiempo. Esta etimología se cita así: «ana, que es «según» y logos, que significa «razón» o proporción, sería «según razón» o, más apropiadamente, «según proporción»».56 La comprensión del texto requiere (1) un acto prudencial, con lo cual se extrae a la hermenéutica de un puro acto técnico, y (2) una confluencia consensual, que introduce a esta disciplina en una consideración cercana a la fusión de horizontes de Gadamer.

Desde la perspectiva de lo prudencial, el Tratado de Hermenéutica Analógica defiende:

Se ha estudiado la analogía entre la lógica y la prudencia en el sentido de que la lógica, dentro de su estructura discursiva y racional o razonable, tiene un aspecto intuitivo y prudencial muy fuerte. Eso hace que en la discusión en la que se busca la convergencia de las tradiciones intervenga un acto prudencial (...) que hace comprender y entenderse (y ese acto es de naturaleza analógica) ${ }^{57}$

Desde lo consensual, la determinación de la verdad de un texto no dependería de un acto solipsista sino que, siguiendo la citada tradición gadameriana, requiere el consenso con el/los otro/s. Ciertamente, Beuchot no se adscribe totalmente a la letra del alemán, puesto que el segundo supera la conceptualización moderna de sujeto con la categoría de horizonte. Para Verdad y método, el acto comprensivo no consiste en el acceso de un sujeto a una realidad mediante un cribado intersubjetivo sino que estriba en la emergencia de un acontecimiento interpretativo donde los dos sujetos (intérprete e interpretado) o las dos entidades hermenéuticas (sujeto y objeto) quedan trascendidos por sus horizontes. El acto hermenéutico, para

niente ver la interpretación como formando poco a poco un hábito o virtud, con aumento interno y externo. Diríase que el primero se hace con el espíritu geométrico, pues el primero es cualitativo y el segundo cuantitativo. Esto último nos mueve a hacer muchos ejercicios interpretativos, y hasta experimentos hermenéuticos; en cambio, lo primero nos mueve a agudizar nuestra mente, como querían los barrocos, o a darle sutileza, como querían los medievales. Todo ello para interpretar con propiedad. Podría hablarse aquí de un desarrollo sintagmático o lineal, horizontal, y de otro paradigmático, vertical, en profundidad. Suele privilegiarse demasiado al primero, pero hace falta resaltar también al segundo" (Beuchot, M. - Arenas-Dolz, F.: Hermenéutica en la encrucijada, op.cit., p.79. Las cursivas son nuestras).

55 Beuchot, M. - Arenas-Dolz, F.: Hermenéutica en la encrucijada, op.cit., p. 86. Las cursivas son nuestras. Se puede profundizar en la historia de la analogía a través del siguiente artículo: Beuchot, M.: "Sobre la analogía y la filosofía actual", Analogía, 1, 1996, pp. 61-76.

56 Beuchot, M. - Arenas-Dolz, F.: Hermenéutica en la encrucijada, op.cit., p. 31.

57 Beuchot, M.: Tratado de hermenéutica analógica, op.cit., p. 57. 
Gadamer, no surge de un consenso intersubjetivo 58 que ayuda a un cribado conducente a la verdad sino de la fusión de dos horizontes, donde no es preciso un cribado conceptual sino un reconocimiento de una verdad abierta inserta en las dos tradiciones puestas en juego y a la que pertenecemos, es decir, gracias a la fusión de dos horizontes.

En este tejido conceptual, Beuchot respeta la supremacía del diálogo en el acto hermenéutico, pero, consideramos, muestra más adhesión a la modernidad (pues admite los sujetos) que el propio Gadamer. A pesar de que el filósofo mexicano señala como objeto hermenéutico a un «dado que se comparte», 59 donde relampaguean los ecos gadamerianos, no olvida la importancia de la argumentación (realizada por un sujeto). «La misma hermenéutica está vinculada con la argumentación (...) en el sentido de que tenemos que comprender de nuestra interpretación». 60

Si Beuchot diese por finalizado su camino con esta hermenéutica mediada por la creación de la interpretación desde la prudencia temporal y el consenso, habría recorrido un loable camino que abriría fronteras innovadoras sobresalientes. Sin embargo, consigue completar su óptica gracias al concepto subtilitas, que progresivamente ha ido concretando en sus trabajos más recientes.

La sutileza era vista como un trasponer el sentido superficial y tener acceso al sentido profundo e inclusive al oculto. O como encontrar varios sentidos cuando parecía haber sólo uno (...) Sobre todo consistía en hallar el sentido auténtico, que está vinculado a la intención del autor, la cual está plasmada en el texto que él produjo. Se trata de captar lo que el autor quiso decir. Es la intención del autor o la intención del texto frente a la mera intención del lector, pues en la interpretación convergen tres cosas: el texto (con el significado que encierra y vehicula), el autor y el lector61

«El método de la hermenéutica es la subtilitas». ${ }^{62}$ Ésta entra en liza, a veces, con el citado consenso si éste aparece desnudo y sin apelación a otras herramientas

\footnotetext{
58 "Cuando se dice que la comunidad o las comunidades ayudan a determinar esa adecuación con la verdad de la traducción o de la interpretación se alude a la intersubjetividad. El único medio que tenemos de cribar la objetividad alcanzable y evitar lo más que se pueda la mera subjetividad es la intersubjetividad, en el diálogo y la discusión con los demás de la misma comunidad o con los pertenecientes a otras comunidades" (Beuchot, M.: Tratado de hermenéutica analógica, op.cit., p. 58).

59 "En el diálogo encuentra Gadamer que se da la auténtica interpretación, porque en cada intervención dialógica se va corrigiendo y perfilando el sentido. No hay principios apodícticos sino un suelo común, algo dado y que se comparte" (Beuchot, M.: Tratado de hermenéutica analógica, op.cit., p. 92).

60 Beuchot, M.: Tratado de hermenéutica analógica, op.cit., p. 87. Las cursivas son nuestras.

61 Ibid, p. 16.

62 Ibid, p. 25.
} 
Al interpretar analógicamente, hemos de buscar, entre las diversas interpretaciones que se han dado, no una extrapolada y excéntrica, dentro de las mismas interpretaciones posibles, sino, dentro del margen de las interpretaciones que además son válidas, la que los otros no han visto y que viene al caso, y que, además, completa y enriquece a las ya existentes. No es, pues, un acto caprichoso de innovación, sino un acto riguroso de intelección, pero abierta, sólo que no completamente, pues se obliga a no salir de las interpretaciones posibles y válidas 63

La subtilitas hunde sus raíces en la filosofía de Duns Escoto, denominado el «Doctor Sutil». Su arte sutil «consistía en encontrar siempre una posibilidad en donde los otros no la veían». 64

Beuchot concreta la subtilitas en la clásica tripartición de sintaxis, semántica y pragmática, que se corresponden con la implicación, la explicación y la aplicación, respectivamente. 65 Unas se encuentran más cerca del texto y otras del sujeto o de las aplicaciones en la realidad del lector. 66

Richard Palmer ha explicado una triple escisión de la hermenéutica basada en un artículo clásico de la disciplina elaborado por Ebeling. Las tres categorizaciones son la hermenéutica como expresar, como afirmar y como traducir. Aluden a su naturaleza inter-mediaria desde los universos desconocidos (o interpretables) a otros conocidos (e interpretados): la hermenéutica explicaría o traduciría los contenidos oscuros (del texto o del autor) al circuito familiar del lector.

\footnotetext{
63 Beuchot, M. - Arenas-Dolz, F.: Hermenéutica en la encrucijada, op.cit.,p. 62-63.

64 Beuchot, M.: Tratado de hermenéutica analógica, op.cit., p.23.

65 Ibid., p. 25.

66 "El primer momento tocaría a la sintaxis, que corresponde a la subtilitas implicandi y no a la subtilitas explicandi. En ese primer paso, se va al significado textual, intratextual e incluso al intertextual (...). Vendrá la subtilitas explicandi, correspondiendo a la semántica. Aquí se va al significado del texto mismo, pero no ya como sentido sino como referencia, es decir en su relación con los objetos, y por ello es donde se descubre cuál es el mundo del texto, esto es, se ve cuál es su referente, real o imaginario. Y finalmente se va a la subtilitas applicandi, correspondiente a la pragmática (lo más propiamente hermenéutico) en la que se toma en cuenta la intencionalidad del hablante, escritor o autor del texto y se lo acaba de insertar en su contexto histórico-cultural. Esto coincide además con tres tipos de verdad que se darían en el texto: una verdad sintáctica como pura coherencia, que puede ser tanto intratextual (interior al texto) como intertextual (con otros textos relacionados); una verdad semántica, como correspondencia con la realidad (presente o pasada) o con algún mundo posible (futuro o imaginario) a que el texto alude, y una verdad pragmática, como convención entre los intérpretes (e inclusive con el autor) acerca de lo que se ha argumentado y persuadido de la interpretación, a pesar de que contenga elementos extratextuales (subjetivos o colectivos)" (Beuchot, M.: Tratado de hermenéutica analógica, op.cit., pp. 24-25).
} 
La hermenéutica como proclamación no se consigue exponer, siempre, con tal claridad. Exigiría un traslado ontológico del sujeto para que al proclamar, proferir o recitar el texto se actualice una comprensión específica y vital del mismo. La comprensión del credo bíblico sería más comprensible (o al menos diferente) para el creyente que para el filólogo latino que se dirigiese a él con metodologías de análisis textual. Sus localizaciones ontológicas ${ }^{67}$ determinan sus actos comprensivos.

Su función no consiste sólo en explicar sino también en proclamar. El pastor, como Hermes y como el sacerdote en Delfos, trae noticias proféticas desde lo divino. En su «decir» o proclamación, él es como Hermes, un «mediador» entre Dios y el hombre. Incluso el mero hecho de decir, afirmar o proclamar es un importante acto de «interpretación» 68

Nos detenemos en esta acepción porque profundiza en la consideración vertical de la hermenéutica a la que estamos dedicando este epígrafe. La hermenéutica no consiste sólo en una herramienta para traernos (objetivamente) el texto a nuestra órbita. Su misión consiste, además, en transportarnos al universo del texto. Este desplazamiento no debería hacerse exclusivamente desde esquemas personales específicos (como el análisis racional); por el contrario, se trata de que dejemos que el cosmos propio del objeto interpretable se nos abra desde la metodología acorde a su esencia idiosincrática.

En el Ión de Platón, aparecen dos sujetos: el rapsoda y el poeta. El rapsoda es mero copiador de los poetas por lo que no entra en la sintonía creadora inherente al poeta, el poeta puede conectarse con la idea trayéndola a la vida, esto es, traduciéndola hermenéuticamente, en tanto en cuanto canta su poema épico. ${ }^{69}$ El poeta es un en-thusiasta, es decir, queda arrobado por fuerzas divinas (y dionisíacas), el rapsoda es mero transmisor de una imagen ya dada, esto es, un fraude puesto que no conecta con la fuente originaria sino con uno de sus transmisores.

Este tramado argumental conduce a una paulatina trascendencia de la palabra como artefacto creado para transmitir un contenido. La palabra, dentro de la hermenéutica como proclamación, guarece en su interior una esencia que no es deudora del intérprete. Esta hermenéutica no exige la aplicación de metodologías para comprender qué dice un texto sino que exhorta a un modo de acceso que restaure la potencia que la palabra tuvo en su origen. En el sentido más heideggeriano, se

67 Esta relocalización es la que habría de gestarse también con la escucha del símbolo en la concepción beuchotiana: "Se requiere que el símbolo nos hable, más que el que nosotros le hablemos. El símbolo es como un templo, hay que ir a él con cierta disposición: si no, no habla, no dice nada" (Beuchot, M.: Teoría de hermenéutica analógica, op.cit., p. 32.

68 Palmer, R.: ¿Qué es la hermenéutica?,op.cit.,p. 32.

${ }^{69}$ Cf. Platón, Ión, 534a y ss. 
empieza a reclamar una palabra como acontecimiento o como casa del ser. La palabra es la que abre mundo. En palabras de Palmer:

La palabra debe dejar de ser palabra (es decir, visual y conceptual) y convertirse en un «acontecimiento». El ser de una obra literaria es un «acontecimiento de palabras» que tiene lugar en forma de interpretación oral 70

Esta nueva tonalidad se evidencia con claridad en la poesía. El poeta busca una palabra apropiada a cada instante, por lo que no sirven los sinónimos. Cada palabra posee una médula particular conectada a cada realidad que se desea expresar. Si el poeta es el que encuentra esa palabra, el hermeneuta es el encargado de restaurar ese sentido al explicar el sentido de la misma, pero también al proclamarla.

La traducción y la explicación son dos modos de exponer los significados ocultos, o borrados por el paso del tiempo, del origen de la palabra. La hermenéutica analógica en su sentido horizontal y en su apertura a través de la subtilitas contribuye a este fin demostrativo. Sin embargo, ¿no será necesaria una profundización hermenéutica (o una síntesis superadora) dedicada a incidir en el mero carácter mostrativo del texto, en dejarlo desnudo, en las puras carnes, o mejor en atraernos a esas carnes para hacerlas tangibles? Dedicaremos a este asunto el siguiente epígrafe; lo que aquí nos ocupa es dilucidar las limitaciones de la hermenéutica analógica para completar esta tarea.

El apartado anterior subrayó que la función de la subtilitas era complementar las visiones profundas de una interpretación, sin negar la apertura horizontal que trascendería el reduccionismo racional o lógico-argumental. De hecho, la misma subtilitas no es pura intuición, como señala la Hermenéutica en la encrucijada.

Se aprende a interpretar con sutileza, y se aprende a argumentar con rigor y habilidad. Usando los términos de Pascal, diríamos que lo primero se hace con esprit de finesse, y lo segundo con esprit géometrique. Hay que reunir los dos espíritus en uno que llamaríamos de sutileza ${ }^{71}$

El acto hermenéutico beuchotiano abreva en ambos espíritus, razón e intuición, en obras precedentes.

Una hermenéutica analógica preserva una parte del univocismo de la hermenéutica positivista, una parte pequeña, según la cual la interpretación requiere de la inteligencia razonadora y explicativa; pero preponderantemente, requiere de la empatía de la razón intuitiva, esto es, de lo que los medievales llamaron -por ejemplo, santo Tomás de

\footnotetext{
70 Palmer, R.: ¿Qué es la hermenéutica?, op.cit., p. 36. Por supuesto, para que esto sea posible, como hemos indicado, es preciso ese traslado esencial del sujeto que proclama la palabra.

71 Beuchot, M. - Arenas-Dolz, F.: Hermenéutica en la encrucijada, op.cit., p. 81.
} 
Aquino- el conocimiento por intelección y el conocimiento por connaturalidad (además de la razón). En cierta manera, hemos de recordar lo que nos legó Aristóteles: que el conocimiento (y la interpretación se da en el rejuego de la intelección, el razonamiento y el sentimiento. Conjunta la intuición y la argumentación 72

La limitación de esta perspectiva, aun valorando muy positivamente la ampliación horizontal y profundizadora de Beuchot respecto a la soberbia moderna, es que no posee (en su actual trazado) la posibilidad de indagar en las densidades o intensidades de la palabra. Probablemente, para penetrar en esta acepción, se pueda realizar por dos caminos: ampliar la teoría o resituar la definición de la hermenéutica beuchotiana (esta última tarea, obviamente, la dejamos al autor). Si la hermenéutica es un proceso de traducción y explicación de textos, el acto de «cantarlos», es decir, entender que ser un profeta de los mismos como medio para comprenderlos escapa de la consideración beuchotiana de hermenéutica. El poeta no sería un hermeneuta, ni tampoco el agente de un recital poético. Sí lo sería el crítico poético o el profesor de literatura en tanto en cuanto expliquen el contenido de los versos. El desafío es animar a ver como hermeneutas al cantante, al pintor, al músico, al poeta o a quien se enfurece en las actualizaciones de sus funciones.

\section{Interpretar III: apertura y densidad intensiva}

\section{IV.1. Ubicando al saber de la experiencia}

Retomemos el punto en que nos encontramos: la hermenéutica analógica y la zambraniana han gestado una crítica al reduccionismo cientificista de la modernidad. Su salida se ha dirigido en tres direcciones.

La primera ha aumentado el espectro de fenómenos a los que dirigir la mirada y ha vuelto a legitimar el número de disciplinas capaces de llevar a término esta tarea. Así ha gestado una apertura horizontal de la verdad y/o de las interpretaciones de los objetos hermeneutizables.

La segunda ha incidido en los medios para profundizar en el contenido de cada uno de los entes de comprensión mediante la subtilitas, que restaura el valor de la intuición, mediante el rescate de la visión directa de contenidos que, a veces, no aparecen en la superficie. Esta argumentación profundizadora se puede hacer desde la instancia zambraniana también. Por ejemplo, la pensadora malagueña aclara que las «notas» del título de su obra Notas de un método «no son anotaciones, sino notas en sentido musical», ${ }^{73}$ esto es, el contenido del libro no reside en las palabras sino

\footnotetext{
72 Beuchot, M.: Tratado de hermenéutica analógica, op.cit., p. 60.

73 Zambrano, M.: Notas de un método, Madrid, Editorial Mondadori, 1989, p. 12.
} 
en la melodía y el ritmo inscrito en ellas, pues «solamente en la melodía puede haber revelación». ${ }^{74}$ Comprender esta obra requiere pues un acto más de visión intuitiva o de intuición auditiva que de comprensión crítica. Asimismo, El pensamiento vivo de Séneca alinea el conocer del sabio en un mapa, gestado a lo largo de múltiples experiencias y que ha requerido (rinde al final) una agudeza análoga a la beuchotiana:

Es una cuestión de oído, una virtud musical la del sabio; es una actividad incesante que percibe, y es un continuo acorde. Es, en suma, un arte. La moral se ha resuelto en estética y como toda estética tiene algo de incomunicable ${ }^{75}$

La tercera huída del cientificismo, la presente, quiere alcanzar una verdad que trascienda la inteligibilidad, la comprensión argumental y explicativa, con la investigación de las dimensiones vivenciales y experienciales de los conceptos. Con ello, el sujeto no sólo va a intentar captar argumental o intuitivamente sino que se va a fusionar con ella y en este acto desvelará un nuevo modelo comprensivo. Su conocimiento no será vehiculado por la dicotomía moderna sujeto-objeto sino que, rompiendo tal distancia, la persona se transforma en un mero portavoz o altavoz de la realidad: se convierte en un profeta de lo que le rodea y del ser en general. Esa fusión permite una comprensión desde dentro de la experiencia, del texto o del sujeto $\mathrm{y}$, por medio de ello, se percibe la densidad o intensidad del contenido. La comprensión se nos antoja como una vivencia desde el propio objeto.

La estructura que nos ayuda a entender esto es el saber de la experiencia.

\section{IV.2. Vida, verdad y saber}

La confesión: género literario $^{76}$ reincide en la crítica a la modernidad. De acuerdo con María Zambrano, en la época inaugurada con Descartes, «el divorcio entre la vida y la verdad filosófica fue ahondándose y fue desapareciendo hasta el rastro de este género de amor que había ido a anidar en la mística». 77 El pensamiento filosófico y el científico generaron sus propias teorías ajenas a la propia vida y se convirtieron en abstracciones no ligadas con o nacidas de la vida. Como vimos, se propone como género literario que lucha contra esto textos como las Confesiones de Agustín de Hipona, las de Rousseau o la Guía de Miguel de Molinos.

Estas obras no se vincula con informaciones desinstaladas de la existencia sino que su carácter bio-gráfico ayuda a ganar evidencias transformadoras de la vida. De

\footnotetext{
74 Ídem.

75 Zambrano, M.: El pensamiento vivo de Séneca, Madrid, Cátedra, 1992, p. 45.

76 Cf. Zambrano, M.: La confesión: género literario, op.cit.

77 Ibid., p. 15.
} 
hecho, el protagonista de una confesión o una guía es una transformación debida a la captación de un tipo de esas evidencias. La evidencia sintetiza un instante «en que la verdad de la mente y de la vida se tocan». 78 De hecho, es bastante pobre en contenido intelectual, pero implica una profunda transformación en el sujeto. 79 Consecuentemente, se distinguen de otras verdades que rápidamente se olvidan porque no marcaron constitutivamente al individuo. 80

Un ejemplo aparece cuando una mujer, después de haber dado a luz, exclama « ¡ahora sé qué significa ser madre!». Otra iluminación evidencial es la de aquel que descubre el significado de la libertad, cuando, a sus sesenta años, ve, por primera vez, el mar. También, habría una evidencia en el hijo sobreprotegido que ha de enfrentarse a su propia vida después de la muerte de su madre.

En todas esas circunstancias, se presencia el destilado de verdades, que podrían concretarse en máximas vitales, que provocan cambios de rumbos existenciales, puesto que parten de experiencias nodales para la persona. ${ }^{81}$

Una descripción fenomenológica análoga al despertar evidencial se encuentra en el Tratado de hermenéutica analógica:

Como una luz que se prende porque se ha atinado a pulsar el botón que enciende. Como una sinapsis. Es cuando se ilumina nuestra capacidad de comprender, cuando las voces que resuenan cobran sentido. Es cuando se siente una extraña comunión con los demás 82

Nuestro interés respecto a este tipo de saber se cifra en su exigencia de convivencia entre saber y vida, a cómo apremian a una fusión con la realidad. Esta fusión sólo es posible porque, como hemos indicado, la verdad surge de una experiencia, de la vivencia de un saber deudor de una circunstancia padecida. ${ }^{83}$ Así, la madre

\footnotetext{
78 Ibid., p. 67.

79 Cf. Ibid., p. 69.

80 Una evidencia puede rescatar de una crisis existencial, puesto que la comprensión que lleva asociada depende de una mudanza de la posición de su agente en el mundo. Ahora bien, una evidencia también podría ser el principio de una desesperación que condujese a la perdición. Por ejemplo, la evidencia surgida de la muerte de una persona muy querida que nos sume en la consternación. En cualquier caso, otra evidencia podría extraer de ella.

81 Hemos estudiado el concepto de experiencia recientemente en varios artículos. Remitimos a dos de los últimos: "La fisiología del saber de la experiencia y los frutos de su posesión" (Barrientos Rastrojo, J.: "La fisiología del saber de la experiencia y los frutos de su posesión", Themata, 44, 2011. pp. 7996) y "El rostro de la experiencia desde la marea orteguiana y zambraniana" (Barrientos Rastrojo, J.: "El rostro de la experiencia desde la marea orteguiana y zambraniana", Endoxa, 25, 2010, pp. 279314).

82 Beuchot, M.: Tratado de hermenéutica analógica, op.cit., p. 191.

83 "Entiendo por experiencia el saber trágico - que Zeus había de aprender padeciendo-. Según Santo Tomás, la mística ¿no es el conocimiento experimental de Dios? Pues en eso estamos queramos o no quedamos. Y una servidora añade siempre: <recibiéndolo> pasivamente, y padeciendo activamente"
} 
entiende su «ser madre" sólo después de dar a luz; este conocimiento dista mucho de la explicación de un libro o de una compañera que le describiese la experiencia. Será imprescindible que el adulto vea el mar para que comprenda qué es la libertad, porque esa experiencia es intransferible $y$, por ende, el conocimiento resultante exige una síntesis en la que el sujeto entra en contacto con la vida. He aquí una distinción radical entre un conocimiento informativo y lo que Zambrano cataloga como «saber». ${ }^{84}$ Ahora bien, esto también habilita a la madre para decirle a su hija: «sólo comprenderás lo que es ser madre cuando tengas tus propios hijos»»". Ítem más: su proclamación «soy madre» dista de la que pudiera hacer su hija adolescente.

Pero, ¿acaso no encontramos este abrazo vida-concepto en nuestro filósofo mexicano? Ciertamente, lo hay: el eje para la reconciliación entre los planos conceptuales y existenciales lo daría el símbolo. Éste «recoge y manifiesta el impulso de la vida, y por ello, si se lo toma en cuenta, puede inyectar a la filosofía esa vida que le falta». ${ }^{85}$ Por ello, tendría mucho sentido realizar un cotejo entre una hermenéutica analógico-simbólica y una razón experiencial basada en el saber evidencial. ${ }^{86}$

En suma, no se trata de comprender un elemento externo para disertar sobre él sino de sumirse en él para proclamarlo, para hablar desde él. ${ }^{87}$ En ese interior, se descubre la verdad o la comprensión en su intensidad máxima.

\section{IV.3. Saber de la experiencia}

En estas atalayas, encontramos a un Beuchot que propone el aprendizaje de la hermenéutica más como un taller de investigación que como un aula de filosofía, ${ }^{88}$ es decir, más como una actividad que genere un hábito que como un conjunto de

(Zambrano, M.: Cartas de la Pièce, op.cit., p. 80. Cursivas de la autora). El conocimiento trágico se cita en El sueño creador como "ese que se adquiere padeciendo el conflicto hasta apurarlo" (Zambrano, M.: El sueño creado, Madrid: Turner, 1986, p. 79).

84 "Zambrano distingue de forma bastante categórica entre lo que llama "conocimiento", que es el resultado de un método, y "saber", como algo que "nace de una pasión, es decir, de un padecer la verdad de la vida antes de que se presente, de haberla concebido como todo lo que se concibe antes de que nazca" (Maillard, Ch.: La creación por la metáfora, op.cit., p. 48).

85 Beuchot, M.: Tratado de hermenéutica analógica, op.cit., p. 194. İtem más: el símbolo "crea una identidad cultural", vincula con el grupo y da sentido de pertenencia (Beuchot, M.: Hermenéutica analógica, símbolo, mito y filosofía, op.cit., p. 13), "el símbolo congregaba a la gente, la hacía reconocerse, la reunía (lo opuesto al symbolo es el diabolo, que es desunión, desencuentro y desvarío)" (p. 47, las cursivas son del autor).

86 Precisamente, a ello, estamos dedicando nuestra investigación más actual.

87 Se podría intentar pensar más allá de lo ya escrito por Beuchot a partir de su defensa de que se piense "con todo el hombre" (Beuchot, M.: Las caras del símbolo. El icono y el ídolo, Madrid, Caparrós editores, 1999, p.15).

88 Cf. Beuchot, M.: "La creatividad hermenéutica. Respuesta a Raúl Alcalá", en Beuchot, M. - Velasco Gómez, A.: Interpretación diálogo y creatividad. Quintas jornadas de hermenéutica, México DF, UNAM, 2003, p. 32. 
lecciones memorizadas y sin implicación existencial. El acto hermenéutico, al ser más que una aplicación de técnicas, esto es, al incluir la necesidad de aprender la subtilitas, requiere un aprendizaje (para modelar la visión) que excede a lo técnico.

Al taller entramos como aprendices para trabajar con un maestro para aprender de él y de los demás alumnos el arte del que se trata. Así se adquiere el arte de la interpretación. Puede que alguien sea buen hermeneuta de manera innata, como hay también buenos poetas o buenos oradores por naturaleza; pero el estudio los hará mejorar. Y mucho más el estudio compartido, dentro de una comunidad hermenéutica o escuela, dentro de una tradición 89

Este emplazamiento coincide con el proceso a sufrir por el aprendiz para desarrollar una intuición hermenéutica maestra, que vemos a continuación.

La primera parada de este recorrido sería la opacidad de aquello que se quiere entender. Después de luchar contra la confusión de buscar respuesta para escapar de lo desapacible de no tener claridad sobre su tema, «cuando ha llegado a un punto en que ni lamentarse puede y su sentir aparece desvalido», 90 se naufraga. El naufragio implica la renuncia a seguir luchando a seguir nadando para evitar hundirse. Entonces, sólo queda la espera humilde de una luz que nos descubra una clave para emerger. En ella, nuestra única labor es la de aceptar lo que viene. Entonces, la comprensión aparece. En síntesis, el sendero del aprendiz incluye cuatro instancias básicas: opacidad, naufragio, espera humilde y visión evidencial. Todas ellas ayudan a una nueva comprensión. Esa comprensión depende del padecimiento de experiencias y de su aceptación. Gracias al mismo, se abren nuevas densidades en los contenidos que antes eran visibles pero no comprensibles.

Notas de un método deduce otra escala para alcanzar esas verdades esenciales. Se repite el esquema aunque la pisada final del peregrinaje es más transparente: perderse, encontrarse y entender el camino. ${ }^{91}$ Esa comprensión final es la que, después, se concretará en máximas o verdades vivenciales que dirigen al propio sujeto y se alzan como destellos de sabiduría que se proponen a otros.

Estos entramados exigen que el conocimiento de la verdad o de la interpretación de un texto nos ponga en contacto con él. Siguiendo a Gadamer, Richard Palmer realiza una reprobación a los críticos de arte que se restringen a analizar conceptualmente obras de arte sin entablar un diálogo que los traslade a la propia obra. ${ }^{92}$

\footnotetext{
89 Beuchot, M. - Arenas-Dolz, F.: Hermenéutica en la encrucijada, op.cit., p. 80.

90 Zambrano, M.: Notas de un método, op.cit., p.21.

91 Ibid, pp. 51-53. La inspiración de las etapas parte del fragmento citado aunque la autora no especifica directamente las fases.

92 Cf. R. Palmer, ¿Qué es la hermenéutica?, op.cit., pp. 273 y ss.
} 


\section{Referencias bibliográficas}

AA.VV.: María Zambrano. Premio Miguel de Cervantes, 1988, Barcelona, Anthropos-Ministerio de Cultura-Dirección General del Libro y Bibliotecas, 1989.

Abellán, J.L.: María Zambrano. Una pensadora de nuestro tiempo, Barcelona, Anthropos, 2006.

Apodaka, E., Merino, L., Villareal, M. (eds.): Crisis y mutaciones de la expertise. Escenarios, políticas y prácticas del conocimiento experto, Zarautz, Ascide, 2012.

Arenas-Dolz, F.: "Hermenéutica, analogía y retórica. Entrevista a Mauricio Beuchot", Endoxa, 20, 2005, p. 677-717.

BARRIEntos RASTROJO, J.: "El rostro de la experiencia desde la marea orteguiana y zambraniana”, Endoxa, 25, 2010, pp. 279-314 .

BARRIEntos RAstrojo, J.: "La fisiología del saber de la experiencia y los frutos de su posesión", Themata, 44, 2011. pp. 79-96.

Beuchot, M.: Ética, Torres asociados, México DF, 2004.

Beuchot, M.: Filosofia Política, Torres Asociados, México DF, 2004.

Beuchot, M.: Hermenéutica analógica, símbolo, mito y filosofia, México DF, UNAM.

Beuchot, M.: "Hermenéutica analógica y crisis de la modernidad", Revista de la UNAM, 567-568, 1998, pp. 10-13.

Beuchot, M.: Las caras del símbolo. El icono y el ídolo, Madrid, Caparrós editores, 1999. Metáforas de nuestra vida. Antropología e interpretación, Huelva, Hergué, 2011.

Beuchot, M.: Perfiles esenciales de hermenéutica, México DF, Fondo de Cultura Económica, 2008.

Beuchot, M.: Posmodernidad, hermenéutica y analogía, México DF, Universidad Intercontinental-Miguel Ángel Porrúa, 1996.

Beuchot, M.: "Sobre la analogía y la filosofía actual", Analogía, 1, 1996, pp. 6176.

Beuchot, M.: Tratado de hermenéutica analógica. Hacia un nuevo paradigma de interpretación, México DF, UNAM-Ítaca, 2000

Beuchot, M., Arenas-Dolz, F.: Hermenéutica en la encrucijada. Analogía, retórica y filosofía, Barcelona, Anthropos, 2008.

FERraris, M.: Historia de la hermenéutica, trd. Jorge Pérez de Tudela Velasco, Madrid, Akal, 2000.

Feyerabend, P.: Contra el método, tr. Eduardo Subirats Rüggeberg, Barcelona, Planeta De-Agostini S. A., 1993.

GRODIN, J.: Introducción a la hermenéutica filosófica, Barcelona, Herder, 1999. 
MAILlARD, Ch.: La creación por la metáfora. Introducción a la razón-poética, Barcelona, Anthropos, 1992.

Mannheim, K.: Ideología y utopía, tr. Salvador Echevarria, Fondo de Cultura Económica, Madrid, 1997.

Marset, J.C.: María Zambrano. I. Los años de formación, Sevilla, Fundación José Manuel Lara, 2004.

PAlmer, R.: ¿Qué es la hermenéutica? Teoría de la interpretación en Schleiermacher, Dilthey, Heidegger y Gadamer, tr. Beatriz Domínguez Parra, Madrid, Arcolibros, 2002.

Platón, Ión en Diálogos I, trd. J. Calonge, E. Lledó y C. García Gual, Madrid, Gredos, 1985.

Zambrano, M.: Cartas de la Pièce (correspondencia con Agustín Andreu), Valencia, Pretextos-Universidad Politécnica de Valencia, 2002.

Zambrano, M.: De la aurora, Madrid, Tabla Rasa, 2004.

Zambrano, M.: El pensamiento vivo de Séneca, Madrid, Cátedra, 1992.

ZAMBrano, M.: El sueño creado, Madrid: Turner, 1986.

ZAMBRANO, M.: España, sueño y verdad, Barcelona, Edhasa, 2002.

Zambrano, M.: Filosofía y educación, Málaga, Ágora, 2007.

Zambrano, M.: Filosofia y poesía, Madrid, Fondo de Cultura Económica, 2001.

ZAMBRAnO, M.: La agonía de Europa, Madrid, Trotta, 2000.

ZAMBRANO, M.: La confesión: género literario, Madrid, Siruela, 1995.

ZAMBRANO, M.: Las palabras del regreso, Salamanca, Amaru ediciones, 1995.

Zambrano, M.: Los bienaventurados, Madrid, Siruela, 2004.

Zambrano, M.: Notas de un método, Madrid, Editorial Mondadori, 1989.

Zambrano, M.: Pensamiento y poesía en la vida española, Madrid, Endymion, 1996.

Zambrano, M.: Persona y democracia, Madrid, Siruela, 1996.

Zambrano, M.: Senderos. Los intelectuales en el drama de España. La tumba de Antígona, Barcelona, Anthropos, 1989.

José Barrientos Rastrojo

Universidad de Sevilla

barrientos@us.es 